\title{
Targeted delivery of anti-inflammatory and imaging agents to microglial cells with polymeric nanoparticles.
}

Celina Cahalane ${ }^{1}$, Jason Bonezzi ${ }^{2}$, John Shelestak ${ }^{3}$, Robert Clements ${ }^{3}$, Aliaksei Boika ${ }^{2}$, Yang H. Yun ${ }^{*}$, and Leah P. Shriver ${ }^{1^{*}}$

${ }^{1}$ Departments of Chemistry and Biology, University of Akron, Knight Chemical Laboratories and Auburn Science and Engineering, Akron, $\mathrm{OH} 44325$, United States

2 Department of Chemistry, University of Akron, Knight Chemical Laboratories, Akron, $\mathrm{OH} 44325$, United States

${ }^{3}$ Department of Biological Sciences, Kent State University, Cunningham Hall, Kent, OH 44242, United States

${ }^{4}$ Department of Biomedical Engineering, University of Akron, Olson Research Center, Akron, OH 44325, United States

*To whom correspondence should be addressed:

Department of Chemistry and Biology, University of Akron, Knight Chemical Laboratories and Auburn Science and Engineering, Akron, OH 44325, United States. Phone: 330-972-6940 Fax: 330-972-6085 Email: 1shriver@uakron.edu

Department of Biomedical Engineering, University of Akron, Olson Research Center, Akron, Ohio 44325, United States. Phone: 330-972-6619 Fax: 330-374-8834 Email: yy@uakron.edu 


\section{Supporting Information}

A

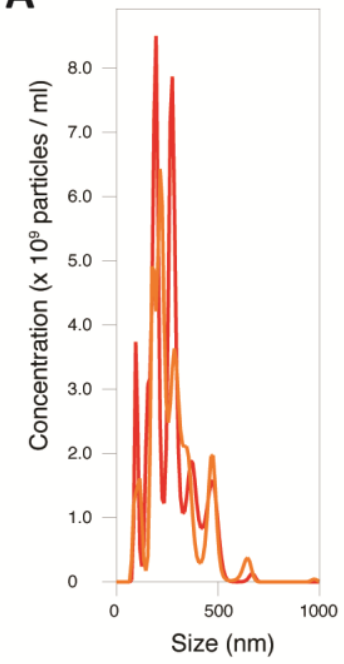

C

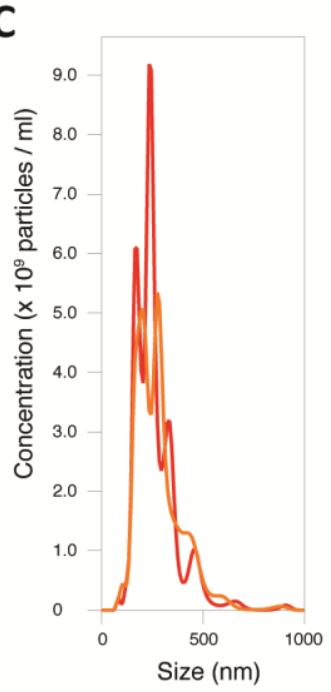

B

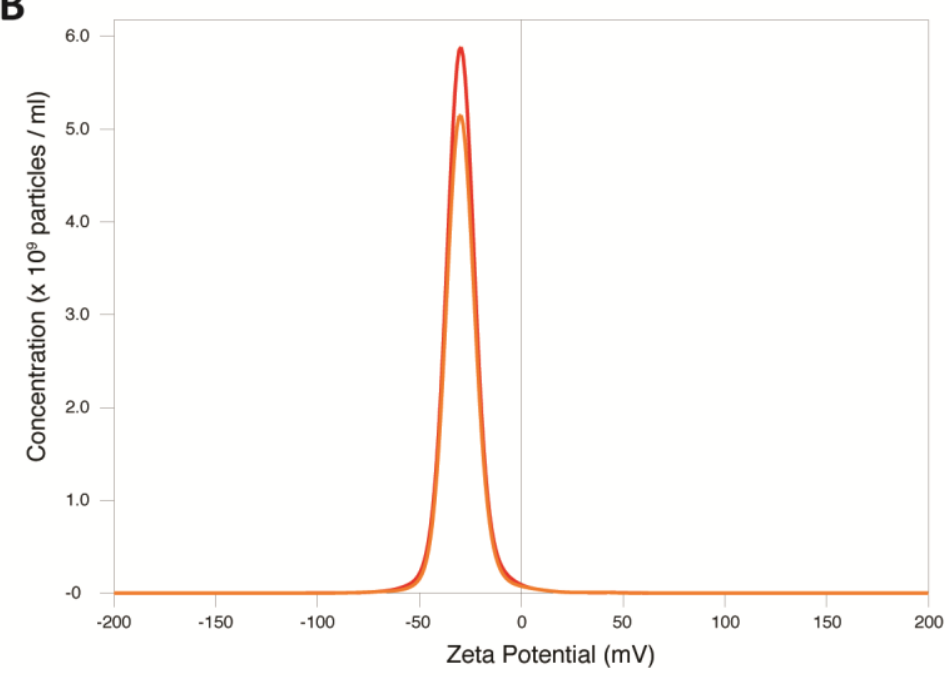

D

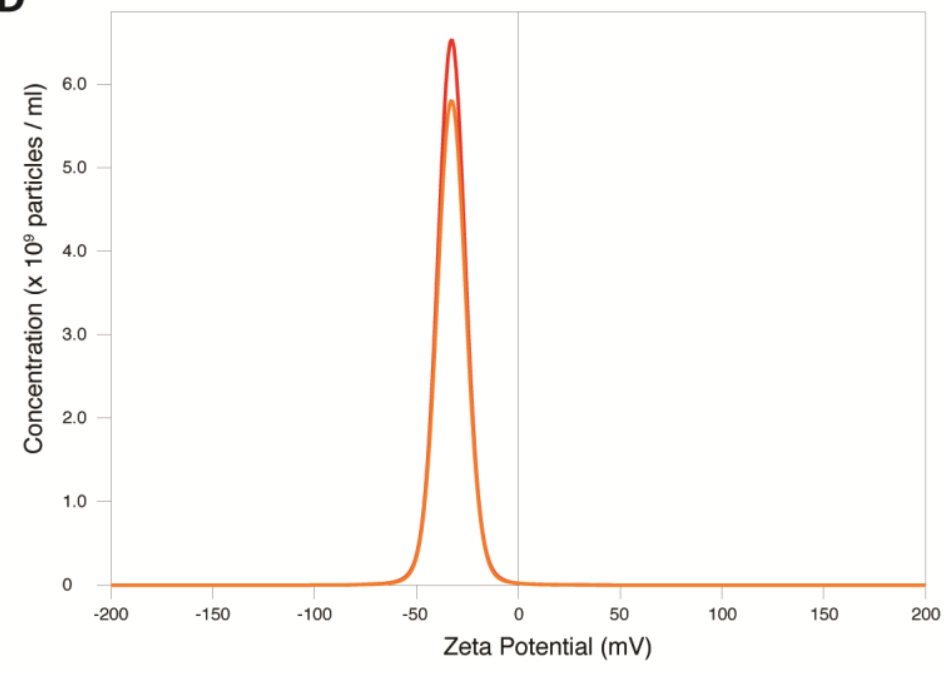

Supplementary Figure 1. Size distribution and zeta-potential analysis of LTP-Gd[DTPA] and LTP-Rol formulations. Mean value for LTP-Gd[DTPA] size (A) is $269.2+/-5.4 \mathrm{~nm}$; zeta-potential (B) is $-29.3+/-0.0$ $\mathrm{mV}$. For LTP-Rol nanoparticles: mean value for size (C) is $273.3+/-7.7 \mathrm{~nm}$; zeta-potential (D) is $-32.7+/-0.0$ $\mathrm{mV}$. 


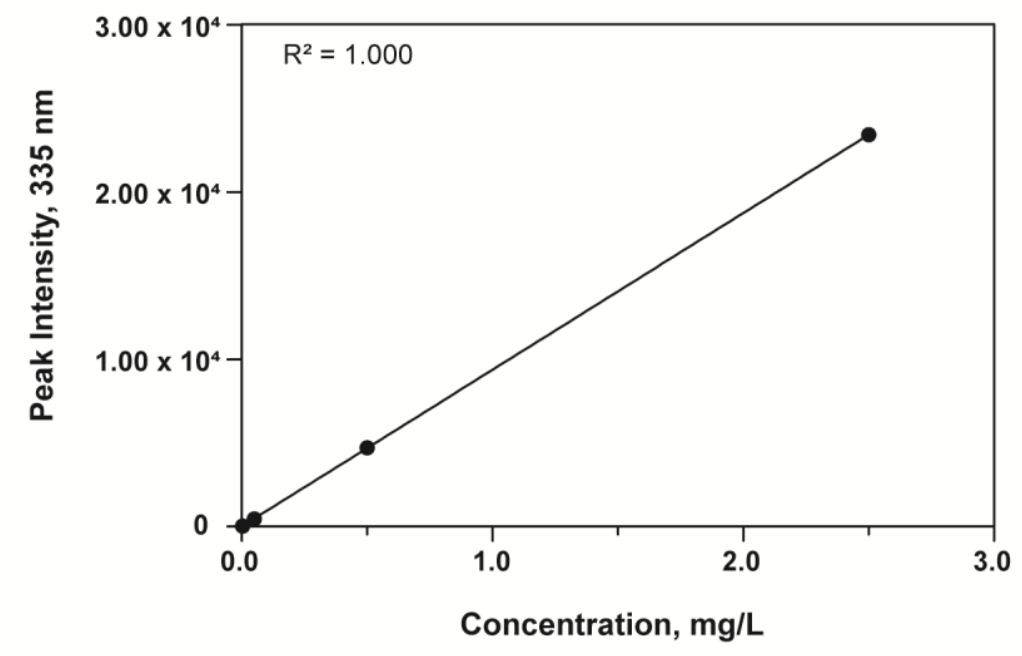

Supplementary Figure 2. Standard curve for gadolinium by ICP-OES $(335 \mathrm{~nm})$

\begin{tabular}{|c|c|c|c|c|c|}
\hline & $\begin{array}{c}\text { ICP-OES } \\
\text { results } \\
(\mathrm{mg} / \mathrm{L})\end{array}$ & $\begin{array}{c}\text { NP } \\
\text { concentration } \\
(\mathrm{mg} / \mathrm{L})\end{array}$ & $\begin{array}{c}{[\mathrm{Gd} / \mathrm{NP}]} \\
(\mathrm{ng} / \mathrm{mg})\end{array}$ & $\begin{array}{c}\text { Theoretical } \\
{[\mathrm{Gd} / \mathrm{NP}]} \\
(\mathrm{ng} / \mathrm{mg})\end{array}$ & $\begin{array}{c}\text { Loading } \\
\text { efficiency } \\
(\% \mathrm{w} / \mathrm{w})\end{array}$ \\
\hline $\begin{array}{c}\text { LTP }- \\
\text { Gd[DTPA] }\end{array}$ & 0.04273 & 360 & 119 & 10,000 & 1.2 \\
\hline $\begin{array}{c}\text { PLGA }- \\
\text { Gd[DTPA] }\end{array}$ & 0.14713 & 300 & 491 & 50,000 & 0.98 \\
\hline
\end{tabular}

Supplementary Table 1. Loading efficiency of LTP and PLGA nanoparticles with Gd[DTPA] as determined by ICP-OES. 

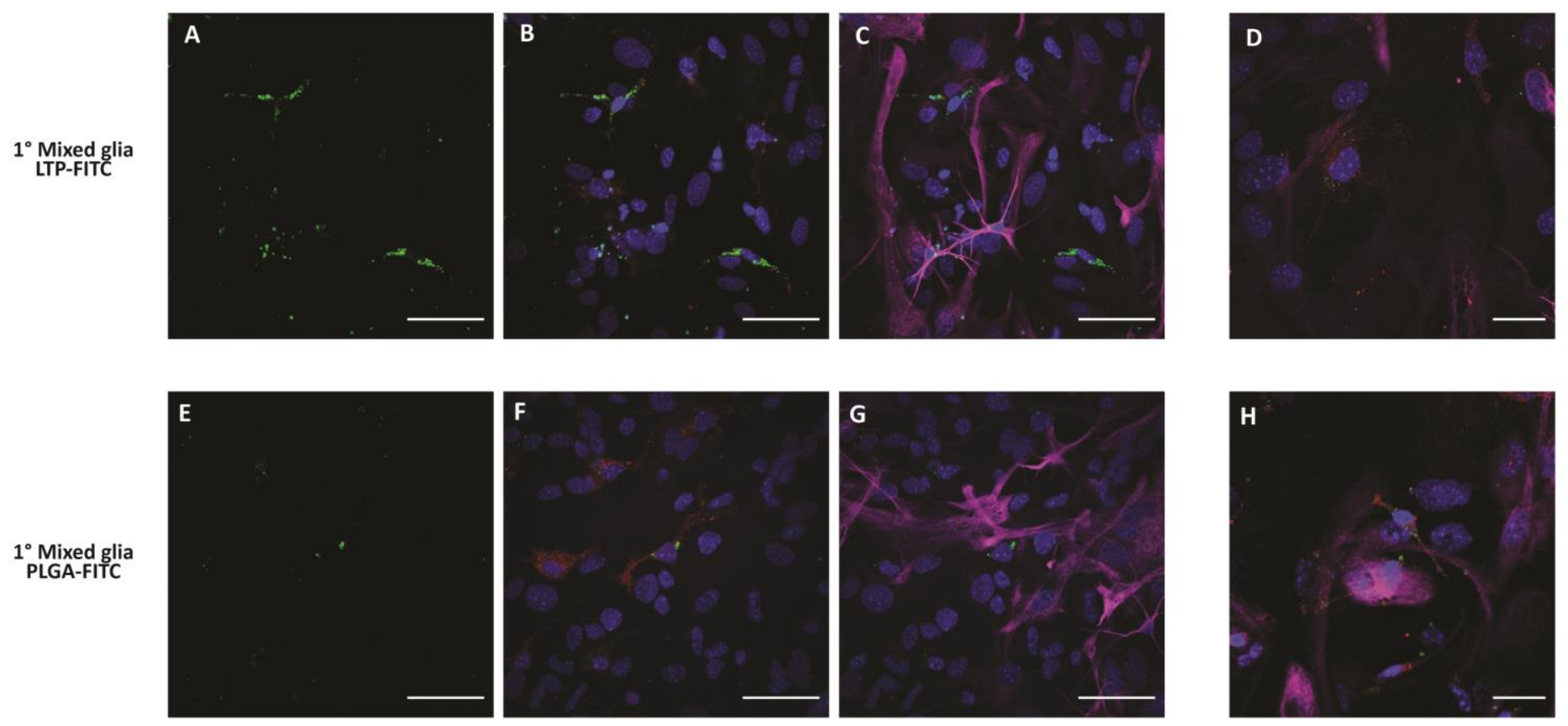

Supplementary Figure 3. Preferential uptake of nanoparticles by microglia in mixed glial cultures. LTP-FITC (A) and PLGA-FITC (E) nanoparticles are taken up by microglia (B, LTP-FITC) (F, PLGA-FITC) more readily than by astrocytes (C, LTP-FITC) (G, PLGA-FITC). Magnification $=60 X$, scale bars represent $50 \mu \mathrm{m} .100 \mathrm{X}$ magnification of preferential uptake of LTP-FITC (D) and PLGA-FITC (H) nanoparticles by microglia. Scale bars represent $20 \mu \mathrm{m}$. (blue = DAPI, nucleus; red = anti-F4/80, microglia; green = FITC, nanoparticles; magenta $=$ anti-GFAP, astrocytes).

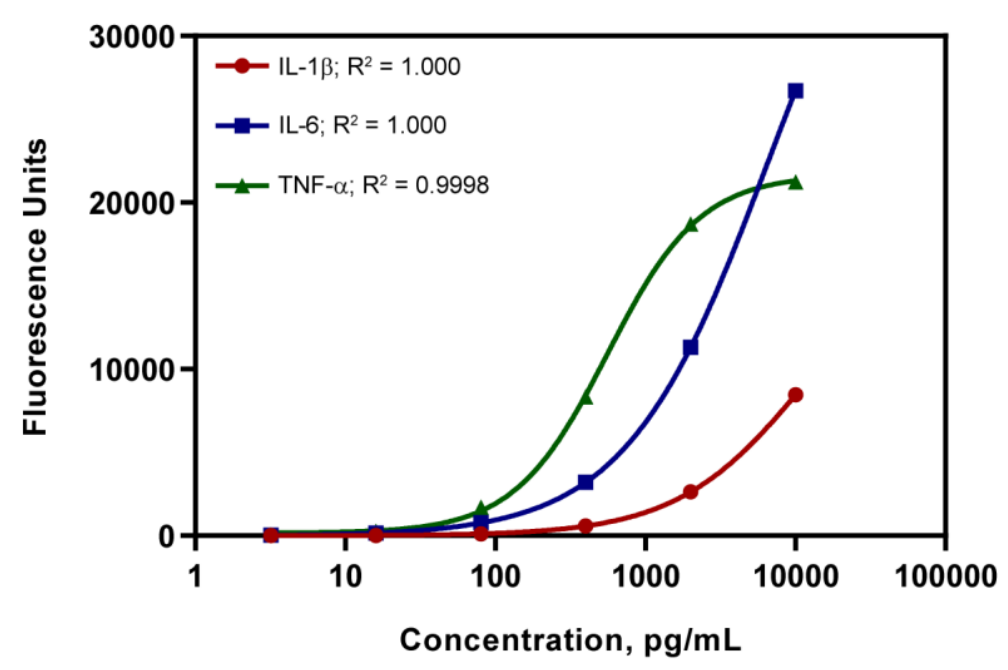

Supplementary Figure 4. Standard curves for the cytokine multiplex assay using 4PL regression 